\title{
Blue Glow Sticks: Cinnamic Acids and Arylacrylonitriles with Liquid-Crystalline Properties and Highly Fluorescent
}

\author{
Aline Tavares, ${ }^{a}$ Rebeca O. Costa, ${ }^{\oplus b}$ Caroline S. B. Weber, ${ }^{a}$ Thiago Cazati, ${ }^{(i c}$ \\ Marco A. Ceschi, ${ }^{a}$ André A. Vieira ${ }^{\circledR *, b}$ and Aloir A. Merlo ${ }^{\circledR} *, a$ \\ ${ }^{a}$ Instituto de Química, Universidade Federal do Rio Grande do Sul, 91501-970 Porto Alegre-RS, Brazil \\ ${ }^{b}$ Instituto de Química, Universidade Federal da Bahia, 40170-115 Salvador-BA, Brazil \\ ${ }^{c}$ Departamento de Física, Universidade Federal de Ouro Preto, 35400-000 Ouro Preto-MG, Brazil
}

\begin{abstract}
Five new $\pi$-conjugated chromophores derived from acrylic acid and acrylonitrile were synthesized and their thermal and photophysical behaviors were analyzed. They were designed and synthesized through Knoevenagel condensations between arylacetylenebenzaldehydes and a methylene group activated from cyanoacetic and malonic acids. The characterization of the target compounds was performed by Fourier transform infrared spectroscopy (FTIR), ${ }^{1} \mathrm{H}$ nuclear magnetic resonance (NMR), ${ }^{13} \mathrm{C}$ NMR, thermogravimetric analysis (TGA), absorption and emission spectroscopy techniques. Arylcinnamic acids were obtained as pure $E$-isomers. On the other hand, arylacrylonitrile was obtained as a mixture of $E / Z$-isomers and the pure $E$-isomer was isolated in chromatographic columns. The liquid crystal properties were investigated through differential scanning calorimetry and polarized optical microscopy. All chromophores displayed smectic and nematic mesophases. These materials displayed intense fluorescence under UV-Vis light excitation. The maximum absorption peaks were observed between $342-356 \mathrm{~nm}$ while emission varied from 428 to $460 \mathrm{~nm}$ in chloroform solution. Higher values for the quantum fluorescence yield were associated with acrylic acids compared to arylacrylonitriles. The solvatochromism studies of the materials showed a significant increase in the red-shift of the fluorescence spectra as the polarity of the solvent increased. In some cases, a variation in the emission wavelength from the blue to the green region of the spectrum was observed.
\end{abstract}

Keywords: Knoevenagel condensation, liquid crystal, fluorescence, quantum yields, solvatochromism

\section{Introduction}

Acrylic acid and acrylonitrile are important $\pi$-conjugated chromophores for manufacturing. As C3 chemical building blocks, they have the potential to provide several commodities for manufacturing polymers, medicines, cosmetics and food. ${ }^{1}$ Their aryl derivatives are interesting chemicals for many functions and applications. ${ }^{2-4}$ Cinnamic acid and its derivatives are found in many natural products including coffee beans, tea, yerba mate and cocoa. ${ }^{5}$ Although arylacrylonitriles ${ }^{6,7}$ are less common in nature than cinnamic derivatives they are important molecule targets for synthesis, considering their wide range of promising biological properties. ${ }^{89}$ In academic and technological research they are used intensively in photoresponsive materials, ${ }^{10-12}$ bowl-

*e-mail: andreqmc@gmail.com; aloir.merlo@ufrgs.br shaped fluorescent liquid crystals, ${ }^{13,14} \mathrm{H}$-bonded liquid crystals with enantiotropic blue phases, ${ }^{15}$ liquid crystal dimers, ${ }^{16,17}$ structure and mesomorphism correlations, ${ }^{18}$ hybrid liquid crystals, ${ }^{19}$ photodimerization reactions, ${ }^{20}$ photoinduced orientation of liquid crystalline copolymer films by reversible addition-fragmentation chain transfer (RAFT) polymerization, ${ }^{21}$ photosensitive polyimide used in the photoalignment layer, ${ }^{22}$ photocrosslinkable thermotropic liquid crystal copolyesters ${ }^{23}$ and piezochromic fluorophores. ${ }^{24}$

One of the most famous families of $\pi$-conjugated chromophores, widely used in the field of functional organic materials, is that of the cyanostilbene chromophore, $[-\mathrm{ArCH}=\mathrm{C}(\mathrm{CN}) \mathrm{Ar}-] .{ }^{25,26} \pi$-Conjugated systems based on cyanostilbene and its derivatives represent a special family of chromophores in which the photophysical properties can be adjusted in response to a variety of external stimuli, such as viscosity, temperature, pressure, $\mathrm{pH}$ and light. ${ }^{27,28}$ 
Elongated molecules containing electron-donor and acceptor groups connected by a bridge-like rigid arylacetylene group have a large extension of the electronic conjugation (structure donor- $\pi$ linker-acceptor (D- $\pi$-A)), affording opportunities for exploration in the field of photoresponsive materials. In previous publications, ${ }^{13,19}$ cinnamic acid and its derivatives have been reported as important promoters of mesomorphism. However, for arylacrylonitriles the mesomorphism is less common or even absent. Moreover, due to the $\pi$-conjugated system photophysical features can be explored in parallel with liquid crystal properties.

In this study, we report the synthesis and characterization of five different rod-like molecules as a result of Knoevenagel condensation between aromatic aldehydes and activated methylene groups. Arylcinnamic acids were obtained as the pure $E$-isomers, while arylacrylonitriles were obtained as $E / Z$-isomer mixtures and the pure $E$-isomer was then isolated in chromatographic columns. The rigid $\pi$-conjugated core of these materials is composed of 4- $n$-alcoxydiphenylacetylene (tolane unit) or 6-n-alcoxynaphthylphenyl-acetylene. The thermal and photophysical properties of all of the compounds were studied in order to investigate the structure-property relationships. The general molecular structure of the synthesized family of $\pi$-conjugated chromophores $\mathbf{8}$ and $\mathbf{9}$ (arylacrylic acid) and 10, 11 and $\mathbf{1 2}$ (arylacrylonitrile) is shown in Scheme 1.
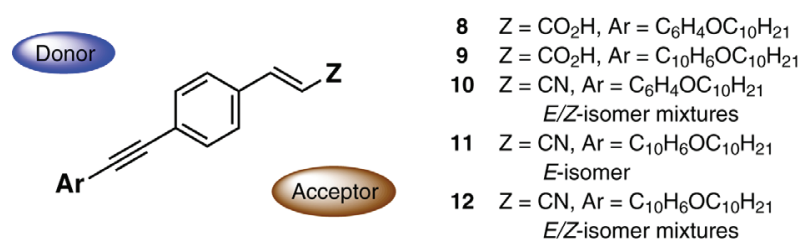

Scheme 1. General structure of compounds 8-12.

\section{Experimental}

\section{Materials and reagents}

The solvents used in the chemical synthesis were purchased from commercial suppliers (Sigma-Aldrich Co, Pró-Análise Cia and Mercolab Cia; Porto Alegre, Brazil) and were purified according to common procedures. ${ }^{29}$ Other chemicals and reagents were commercially available and used as received. Extracts were dried with anhydrous $\mathrm{Na}_{2} \mathrm{SO}_{4}$ and filtered before removal of the solvent by evaporation. The bis-(triphenylphosphine) palladium(II) chloride $\left(\left[\mathrm{PdCl}_{2}\left(\mathrm{PPh}_{3}\right)_{2}\right]\right)$ was synthesized following a known procedure described in the literature. ${ }^{30}$

\section{Characterization}

Proton and carbon nuclear magnetic resonance spectra ( ${ }^{1} \mathrm{H}$ and ${ }^{13} \mathrm{C}$ NMR) were obtained with $\mathrm{CDCl}_{3}$ as a solvent on a Varian $400 \mathrm{MHz}$ spectrometer. Chemical shifts are given in parts per million $(\delta)$ and are relative to the signal of tetramethylsilane $\left(\delta 0 \mathrm{ppm}\right.$ for $\left.{ }^{1} \mathrm{H}\right)$ as internal reference for solutions in $\mathrm{CDCl}_{3}$. The NMR spectroscopic data are reported as follows: $\mathrm{CDCl}_{3}\left(\delta 7.26 \mathrm{ppm}\right.$ for ${ }^{1} \mathrm{H}$ or $\delta 77.1 \mathrm{ppm}$ for ${ }^{13} \mathrm{C}$ ) and dimethyl sulfoxide (DMSO- $d_{6}, \delta 2.50 \mathrm{ppm}$ for ${ }^{1} \mathrm{H}$ or $\delta 39.5 \mathrm{ppm}$ for $13 \mathrm{C}$ ). Multiplicities are reported according to the following abbreviations: $\mathrm{s}=$ singlet, $\mathrm{d}=$ doublet, $\mathrm{t}=$ triplet, $\mathrm{q}=$ quartet, $\mathrm{m}=$ multiplet, $\mathrm{br}=$ broad. Coupling constants $(J)$ are given in $\mathrm{Hz}$. Ultraviolet visible spectra (UV-Vis) of the $10^{-5} \mathrm{M}$ solutions were obtained using a Varian Cary 50 UV/Vis Spectrophotometer. Fluorescence spectra were measured using a Shimadzu RF5301pc spectrofluorophotometer equipped with a xenon lamp and $1.0 \mathrm{~cm}$ quartz cells. The emission-slit widths were 5 and $5 \mathrm{~nm}$, respectively. The characterization by Fourier transform infrared spectroscopy (FTIR) was measured using a Varian 640-IR spectrometer $(\mathrm{KBr})$ between 4000 and $500 \mathrm{~cm}^{-1}$ and with a resolution of $4 \mathrm{~cm}^{-1}$. All spectra were performed with 16 scans and are given in wavenumbers $\left(\mathrm{cm}^{-1}\right)$. Low-resolution mass spectra (MS) were obtained with a Shimadzu GC-MS-QP5050 mass spectrometer interfaced with a Shimadzu GC-17A gas chromatograph equipped with a 30 meter Rtx-5MS $(0.25 \times 0.25 \mathrm{~mm})$ capillary column. The column temperature started at $80{ }^{\circ} \mathrm{C}$ and held for $2 \mathrm{~min}$, ramped to $250{ }^{\circ} \mathrm{C}$ at a rate of $10^{\circ} \mathrm{C} \mathrm{min}^{-1}$, held for $2 \mathrm{~min}$, ramped to $330^{\circ} \mathrm{C}$ at $20^{\circ} \mathrm{C} \mathrm{min}^{-1}$ and held for $10 \mathrm{~min}$. The melting points, phase transition temperatures and mesomorphic textures were taken using an Olympus BX43 microscope equipped with a Mettler Toledo FP82HT Hot Stage with an FP90 Central Processor at a heating/cooling rate of $10^{\circ} \mathrm{C} \mathrm{min}^{-1}$ (magnification: 10x). Carbon, hydrogen, and nitrogen $(\mathrm{CHN})$ elemental analysis were performed on a PerkinElmer 2400 CHN Elemental Analyzer. Differential scanning calorimetry analyses (DSC) were performed on a Q2000 (TA instruments) with an ultra-pure nitrogen flow of $50 \mathrm{~mL} \mathrm{~min}{ }^{-1}$ with a heating rate of $10^{\circ} \mathrm{C} \mathrm{min}^{-1}$ and Tzero aluminum hermetic pan. The thermal degradation was carried out by thermogravimetric analysis (TGA) on a TGA Discovery (TA Instruments) with an ultra-pure nitrogen flow of $25 \mathrm{~mL} \mathrm{~min}^{-1}$ from 40 up to $500{ }^{\circ} \mathrm{C}$ with a heating rate of $10{ }^{\circ} \mathrm{C} \mathrm{min}^{-1}$ and platinum-HT pan.

\section{Synthesis description}

Synthesis of 4-[(4-decyloxyphenyl)ethynyl]benzaldehyde (4) Sonogashira's coupling: a one-neck round-bottom 
flask equipped with septum stoppers was charged with dry $\mathrm{NEt}_{3}(30 \mathrm{~mL})$, 4-bromobenzaldehyde (3) (2.4 g, $13.0 \mathrm{mmol})$, alkyne $\mathbf{1}(5.0 \mathrm{~g}, 19.0 \mathrm{mmol})$, copper(I) iodide (CuI) $\left(12.0 \mathrm{mg}, 6.3 \times 10^{-5} \mathrm{~mol}\right)$, triphenylphosphine $\left(\mathrm{PPh}_{3}\right)$ $\left(76.0 \mathrm{mg}, 2.9 \times 10^{-4} \mathrm{~mol}\right)$ and bis-(triphenylphosphine) palladium(II) chloride $\left(\left[\mathrm{PdCl}_{2}\left(\mathrm{PPh}_{3}\right)_{2}\right]\right)(40.0 \mathrm{mg}$, $\left.5.8 \times 10^{-5} \mathrm{~mol}, 0.3 \mathrm{~mol} \%\right)$ under argon atmosphere. The mixture was heated under reflux for $48 \mathrm{~h}$. After the suspension to reach room temperature, it was filtered through a Celite ${ }^{\circledR}$ pad and washed with $\mathrm{CH}_{2} \mathrm{Cl}_{2}$. The filtrate was extracted with $\mathrm{H}_{2} \mathrm{O}(3 \times 50 \mathrm{~mL})$ and the organic extracts were dried $\left(\mathrm{Na}_{2} \mathrm{SO}_{4}\right)$ and evaporated off. The solid was recrystallized twice from ethanol and once from hexane affording the product. Yield: $3.6 \mathrm{~g}$ $(77 \%)$ as a yellow solid; FTIR (KBr) $v_{\max } / \mathrm{cm}^{-1} 2951$, 2918, 2846, 2738, 2210, 1699, 1597, 1514, 1282, 1244, 1205, 1068, 833, 680; ${ }^{1} \mathrm{H}$ NMR (400 MHz, $\left.\mathrm{CDCl}_{3}\right) \delta$ $0.91\left(\mathrm{~m}, 3 \mathrm{H}, \mathrm{CH}_{3}\right), 1.20-1.58\left(\mathrm{~m}, 14 \mathrm{H},\left(\mathrm{CH}_{2}\right)_{7}\right), 1.81(\mathrm{~m}$, $\left.2 \mathrm{H}, \mathrm{CH}_{2} \mathrm{CH}_{2} \mathrm{O}\right), 4.00\left(\mathrm{t}, J 6.6 \mathrm{~Hz}, 2 \mathrm{H}, \mathrm{CH}_{2} \mathrm{O}\right), 6.91$ (d, $J 6.0 \mathrm{~Hz}, 2 \mathrm{H}, \mathrm{Ar}), 7.50(\mathrm{~d}, J 6.0 \mathrm{~Hz}, 2 \mathrm{H}, \mathrm{Ar}), 7.66(\mathrm{~d}$, $J 6.0 \mathrm{~Hz}, 2 \mathrm{H}, \mathrm{Ar}), 7.87$ (d, J 6.0 Hz, 2H, Ar), 10.02 (s, $1 \mathrm{H}, \mathrm{CHO}) ;{ }^{13} \mathrm{C}$ NMR $\left(100 \mathrm{MHz}, \mathrm{CDCl}_{3}\right) \delta 14.1,22.7$, 26.0, 29.1, 29.3, 29.4, 29.6, 31.9, 68.1, 87.4, 93.9, 114.2, 114.6, 129.6, 130.1, 131.8, 133.3, 135.0, 159.8, 191.4.

\section{Synthesis of 4-\{[(6-decyloxynaphthalen)-2-yl]ethynyl\} benzaldehyde (5)}

Sonogashira's coupling: a one-neck round-bottom flask equipped with septum stoppers was charged with dry $\mathrm{NEt}_{3}(30 \mathrm{~mL})$, 4-bromobenzaldehyde (3) (2.0 g, $10.8 \mathrm{mmol})$, alkyne 2 (5.0 g, $16.0 \mathrm{mmol})$, copper(I) iodide (CuI) (10.0 mg, 5.2 $\left.\times 10^{-5} \mathrm{~mol}\right)$, triphenylphosphine $\left(\mathrm{PPh}_{3}\right)$ (63.5 mg, $\left.2.4 \times 10^{-4} \mathrm{~mol}\right)$ and bis-(triphenylphosphine) palladium(II) chloride $\left(\left[\mathrm{PdCl}_{2}\left(\mathrm{PPh}_{3}\right)_{2}\right]\right)(34.0 \mathrm{mg}$, $\left.4.8 \times 10^{-5} \mathrm{~mol}, 0.3 \mathrm{~mol} \%\right)$ under argon atmosphere. The mixture was heated under reflux for $48 \mathrm{~h}$. After the suspension to reach room temperature, it was filtered through a Celite ${ }^{\circledR}$ pad and washed with $\mathrm{CH}_{2} \mathrm{Cl}_{2}$. The filtrate was extracted with $\mathrm{H}_{2} \mathrm{O}(4 \times 50 \mathrm{~mL})$ and the organic extracts were dried $\left(\mathrm{Na}_{2} \mathrm{SO}_{4}\right)$ and evaporated off. The solid was recrystallized twice from ethanol and once from hexane affording the product. Yield: $3.4 \mathrm{~g}(51 \%)$ as a yellow solid; FTIR (KBr) $v_{\max } / \mathrm{cm}^{-1} 2919,2850,1687,1604,1471,1388$, 1257, 1211, 1020, 862, 825; ${ }^{1} \mathrm{H}$ NMR (400 MHz, $\left.\mathrm{CDCl}_{3}\right)$ $\delta 0.89\left(\mathrm{~m}, 3 \mathrm{H}, \mathrm{CH}_{3}\right), 1.20-1.58\left(\mathrm{~m}, 14 \mathrm{H},\left(\mathrm{CH}_{2}\right)_{7}\right), 1.87(\mathrm{~m}$, $2 \mathrm{H}, \underline{\mathrm{C}}_{2} \mathrm{CH}_{2} \mathrm{O}$ ), 4.09 (t, J $6.6 \mathrm{~Hz}, 2 \mathrm{H}, \mathrm{CH}_{2} \mathrm{O}$ ), 7.11-7.21 (m, 2H, Ar), 7.52-7.57 (m, 1H, Ar), 7.68-7.76 (m, 4H, Ar), 7.86-7.91 (m, 2H, Ar), 8.02 (s, 1H, Ar), 10.05 (s, 1H, CHO); ${ }^{13} \mathrm{C} \mathrm{NMR}\left(100 \mathrm{MHz}, \mathrm{CDCl}_{3}\right) \delta 14.3,22.8,26.2,29.3,29.4$, 29.6, 29.7, 29.8, 32.1, 68.2, 88.4, 94.5, 106.7, 117.3, 120.1, $127.1,128.4,128.9,129.5,129.7,130.0,131.9,132.1$,
134.7, 135.3, 158.3, 191.5; MS (electrospray ionization (ESI)) $m / z, \mathrm{C}_{29} \mathrm{H}_{32} \mathrm{O}_{2}\left[\mathrm{M}^{+}\right]: 412$.

Synthesis of E-3-[4-(4-decyloxyphenyl)ethynylphenyl] acrylic acid (8)

In a flask fitted with a reflux condenser was added the aldehyde 4 (2.5 g, $6.9 \mathrm{mmol})$, malonic acid (1.6 g, $15.0 \mathrm{mmol})$, pyridine $(7 \mathrm{~mL}, 87.0 \mathrm{mmol})$, and piperidine $(51 \mu \mathrm{L}, 0.5 \mathrm{mmol})$ and refluxed for 2 days. After the solution cool down at room temperature, concentrated $\mathrm{HCl}$ was slowly added and the stirring continued for half an hour. The residue was filtered, washed with $\mathrm{CH}_{2} \mathrm{Cl}_{2}$, and recrystallized twice from ethanol affording the product. Yield: $1.9 \mathrm{~g}(69 \%)$ as a yellow solid; FTIR $(\mathrm{KBr}) v_{\max } / \mathrm{cm}^{-1}$ 3531, 2953, 2920, 2848, 1679, 1516, 1429, 1249, 1022, 985, 837, 653, 536; ${ }^{1} \mathrm{H}$ NMR (400 MHz, $\left.\mathrm{CDCl}_{3}\right) \delta 0.88$ $\left(\mathrm{m}, 3 \mathrm{H}, \mathrm{CH}_{3}\right), 1.16-1.52\left(\mathrm{~m}, 14 \mathrm{H},\left(\mathrm{CH}_{2}\right)_{7}\right), 1.78(\mathrm{~m}, 2 \mathrm{H}$, $\left.\mathrm{C}_{2} \mathrm{CH}_{2} \mathrm{O}\right), 3.97$ (t, J $\left.6.4 \mathrm{~Hz}, 2 \mathrm{H}, \mathrm{CH}_{2} \mathrm{O}\right), 6.43(\mathrm{~d}, 1 \mathrm{H}$, $J 16.0 \mathrm{~Hz}, \underline{\mathrm{HC}}=\mathrm{CH}), 6.87(\mathrm{~d}, 2 \mathrm{H}, J 8.4 \mathrm{~Hz}, \mathrm{Ar}), 7.46(\mathrm{~d}$, $2 \mathrm{H}, J 8.4 \mathrm{~Hz}, \mathrm{Ar}), 7.49$ (s, 4H, Ar), 7.65 (d, 1H, J $16.0 \mathrm{~Hz}$, $\mathrm{HC}=\mathrm{C} \underline{\mathrm{H}}$ ); elemental analysis calcd.: C 80.16, H 7.97, $\mathrm{N} 0.0 \%$; found: C 79.94, H 7.99, N $0.11 \%$.

Synthesis of E-3-\{4-[(6-decyloxynaphthalen)-2-yl] ethynylphenyl\}acrylic acid (9)

In a flask fitted with a reflux condenser was added the aldehyde 5 (312.0 mg, $0.7 \mathrm{mmol})$, malonic acid ( $141.0 \mathrm{mg}$, $1.7 \mathrm{mmol})$, pyridine $(1 \mathrm{~mL}, 12.0 \mathrm{mmol})$, and piperidine $(16 \mu \mathrm{L}, 0.2 \mathrm{mmol})$ and refluxed for 2 days. After the solution cool down at room temperature, concentrated $\mathrm{HCl}$ was slowly added and the stirring continued for half an hour. The residue was filtered and washed with acetone and then purified by silica gel column (230-400 mesh (Merck)) using $\mathrm{CH}_{2} \mathrm{Cl}_{2}$ as eluent. The product was recovered washing the column with DMSO and isolated after crystallization in this solvent. Yield: $0.2 \mathrm{~g} \mathrm{(70 \% )} \mathrm{as}$ a white solid; FTIR (KBr) $v_{\max } / \mathrm{cm}^{-1} 3463,2953,2920$, 2848, 1678, 1625, 1602, 1257, 1217, 1170, 985, 833, 663, 532; ${ }^{1} \mathrm{H}$ NMR $\left(400 \mathrm{MHz}, \mathrm{CDCl}_{3}\right) \delta 0.88\left(\mathrm{~m}, 3 \mathrm{H}, \mathrm{CH}_{3}\right)$, 1.16-1.56 (m, $\left.14 \mathrm{H},\left(\mathrm{CH}_{2}\right)_{7}\right), 1.85\left(\mathrm{~m}, 2 \mathrm{H}, \mathrm{C}_{2} \mathrm{CH}_{2} \mathrm{O}\right), 4.08$ (t, J $\left.6.3 \mathrm{~Hz}, 2 \mathrm{H}, \mathrm{CH}_{2} \mathrm{O}\right), 6.45(\mathrm{~d}, 1 \mathrm{H}, J 16.2 \mathrm{~Hz}, \mathrm{HC}=\mathrm{CH})$, 7.08-7.20 (m, 2H, Ar), 7.48-7.59 (m, 5H, Ar), 7.62-7.75 (m, $2 \mathrm{H}, \mathrm{Ar}+1 \mathrm{H}, \mathrm{HC}=\mathrm{CH}), 7.98(\mathrm{~s}, 1 \mathrm{H}, \mathrm{Ar})$; elemental analysis calcd.: C 81.90, H 7.54, N 0.0\%; found: C 81.36, H 7.23, N $0.16 \%$.

Synthesis of mixture of $E$ and $Z$ isomers 3-[4-(4-decyloxyphenyl)ethynylphenyl]acrylonitrile (10)

In a flask fitted with a reflux condenser was added the acetonitrile $(30 \mathrm{~mL})$, aldehyde $4(1.0 \mathrm{~g}, 2.7 \mathrm{mmol})$, cyanoacetic acid (283.0 mg, $3.3 \mathrm{mmol})$, and morpholine 
$(0.8 \mathrm{~mL}, 9.1 \mathrm{mmol})$ and refluxed for 3 days. After the solution cool down at room temperature a precipitate was formed. It was filtered, washed with hexane, recrystallized from $\mathrm{CH}_{2} \mathrm{Cl}_{2}$ and finally chromatographed on a silica gel column (230-400 mesh (Merck)) using hexane as eluent. The elution was monitored with UV-bench lamp illumination due to blue fluorescence of the compound in the column. Yield: $240 \mathrm{mg}(23 \%)$ of the white solid as a mixture of $E / Z$ (33:67); FTIR (KBr) $v_{\max } / \mathrm{cm}^{-1} 3064,2920$, 2852, 2214, 1595, 1514, 1473, 1286, 1249, 1136, 995, 810, 675, 538; ${ }^{1} \mathrm{H} \mathrm{NMR}\left(400 \mathrm{MHz}, \mathrm{CDCl}_{3}\right) \delta 0.88(\mathrm{~m}, 3 \mathrm{H}$, $\left.\mathrm{CH}_{3}\right), 1.20-1.50\left(\mathrm{~m}, 14 \mathrm{H},\left(\mathrm{CH}_{2}\right)_{7}\right), 1.78\left(\mathrm{~m}, 2 \mathrm{H}, \mathrm{C}_{2} \mathrm{CH}_{2} \mathrm{O}\right)$, 3.97 (t, J $\left.4.8 \mathrm{~Hz}, 2 \mathrm{H}, \mathrm{CH}_{2} \mathrm{O}\right), 5.45$ (d, J $12.0 \mathrm{~Hz}, \mathrm{CH}=\mathrm{CH}$, $Z$-isomer), 5.87 (d, $J 16.0 \mathrm{~Hz}, \mathrm{CH}=\mathrm{CH}, E$-isomer), 6.85 (d, $J 8.8 \mathrm{~Hz}, 2 \mathrm{H}, \mathrm{Ar}$ ), 7.09 (d, J $12.0 \mathrm{~Hz}, \mathrm{CH}=\mathrm{CH}, \mathrm{Z}$-isomer), 7.37 (d, $J 16.0 \mathrm{~Hz}, \mathrm{CH}=\mathrm{CH}, E$-isomer), $7.41(\mathrm{~d}, J 8.4 \mathrm{~Hz}$, 2H, Ar), 7.45 (d, J $8.8 \mathrm{~Hz}, 2 \mathrm{H}, \mathrm{Ar}), 7.52$ (d, J $8.4 \mathrm{~Hz}, 2 \mathrm{H}$, Ar), 7.55 (d, $J 8.4 \mathrm{~Hz}, \mathrm{Ar}, Z$-isomer), 7.78 (d, $J 8.4 \mathrm{~Hz}$, $\mathrm{Ar}, Z$-isomer); ${ }^{13} \mathrm{C}$ NMR $\left(100 \mathrm{MHz}, \mathrm{CDCl}_{3}\right) \delta 14.0,22.6$, $25.9,29.1,29.2,29.3,29.5,29.6,31.8,68.0,87.4,87.5$ (Z-isomer), 92.4 (Z-isomer), 92.6, 95.0 (Z-isomer), 96.4, 114.3 (Z-isomer), 114.5, 117.2 (Z-isomer), 118.0, 126.3 (Z-isomer), 126.6, 127.2, 128.9, 131.6 (Z-isomer), 131.8, 132.5, 132.6 (Z-isomer), 133.0, 147.6 (Z-isomer), 149.5, 159.5 .

Synthesis of (E)-3-\{4-[(6-decyloxynaphthalen)-2-yl]ethynylphenyl\}acrylonitrile (11) and (E/Z)-3-\{4-[(6-decyloxynaphthalen)-2-yl]ethynylphenyl\}acrylonitrile (12)

In a flask fitted with a reflux condenser was added the acetonitrile ( $30 \mathrm{~mL})$, aldehyde 5 (1.0 g, $2.4 \mathrm{mmol})$, cyanoacetic acid $(250.0 \mathrm{mg}, 2.9 \mathrm{mmol})$, and pyridine $(0.5 \mathrm{~mL}, 6.2 \mathrm{mmol})$ and refluxed for 3 days. After the suspension cool down at room temperature, it was filtered and chromatographed on a silica gel column (230-400 mesh (Merck)) using hexane as eluent for one week. The elution was monitored with UV-bench lamp illumination: compound $\mathbf{1 1}$ has yellow fluorescence and eluted first and it was collected as pure $E$-isomer; compound $\mathbf{1 2}$ is yellow and has not fluorescence in the column, and it was collected as mixture of $E / Z$ isomers (32:68). Yield: 11, $200 \mathrm{mg}$ (19\%) as a yellow crystalline solid and $\mathbf{1 2}, 83 \mathrm{mg}(8 \%)$ as a white crystalline solid.

\section{Data for $(E)-\mathbf{1 1}$}

FTIR (KBr) $v_{\max } / \mathrm{cm}^{-1} 3064,2920,2852,2216,1600$, 1469, 1386, 1257, 1213, 1166, 1020, 852, 817; ${ }^{1} \mathrm{H}$ NMR $\left(400 \mathrm{MHz}, \mathrm{CDCl}_{3}\right) \delta 0.89\left(\mathrm{~m}, 3 \mathrm{H}, \mathrm{CH}_{3}\right), 1.20-1.55(\mathrm{~m}$, $\left.14 \mathrm{H},\left(\mathrm{CH}_{2}\right)_{7}\right), 1.85\left(\mathrm{~m}, 2 \mathrm{H}, \underline{\mathrm{C}}_{2} \mathrm{CH}_{2} \mathrm{O}\right), 4.07$ (t, $J 6.6 \mathrm{~Hz}$, $\left.2 \mathrm{H}, \mathrm{CH}_{2} \mathrm{O}\right), 5.88(\mathrm{~d}, J 16.0 \mathrm{~Hz}, 1 \mathrm{H}, \underline{\mathrm{HC}}=\mathrm{CHCN}), 7.10-7.21$ $(\mathrm{m}, 2 \mathrm{H}, \mathrm{Ar}), 7.38(\mathrm{~d}, J 16.0 \mathrm{~Hz}, 1 \mathrm{H}, \mathrm{HC}=\mathrm{CHCN}), 7.43(\mathrm{~d}$,
$J$ 8.4 Hz, 2H, Ar), 7.50-7.60 (m, 3H, Ar), 7.65-7.74 (m, $2 \mathrm{H}, \mathrm{Ar}), 7.98$ (s, 1H, Ar); ${ }^{13} \mathrm{C}$ NMR (100 MHz, $\mathrm{CDCl}_{3}$ ) $\delta$ 14.1, 22.7, 26.1, 29.2, 29.3, 29.4, 29.5, 29.6, 31.9, 68.1, 88.3, 93.2, 96.7, 106.5, 117.3, 118.1, 119.9, 126.5, 126.9, $127.3,128.3,128.7,129.3,131.6,132.1,132.8,134.4$, 149.6, 158.1.

\section{Data for $(E / Z)-12$}

FTIR (KBr) $v_{\max } / \mathrm{cm}^{-1} 3062,2920,2852,2218,1600$, 1469, 1386, 1257, 1213, 1166, 1022, 968, 856, 813; ${ }^{1} \mathrm{H} \mathrm{NMR}\left(400 \mathrm{MHz}, \mathrm{CDCl}_{3}\right) \delta 0.89\left(\mathrm{~m}, 3 \mathrm{H}, \mathrm{CH}_{3}\right), 1.20-$ $1.55\left(\mathrm{~m}, 14 \mathrm{H},\left(\mathrm{CH}_{2}\right)_{7}\right), 1.85\left(\mathrm{~m}, 2 \mathrm{H}, \underline{\mathrm{C}}_{2} \mathrm{CH}_{2} \mathrm{O}\right), 4.07(\mathrm{t}$, $\left.J 6.6 \mathrm{~Hz}, 2 \mathrm{H}, \mathrm{CH}_{2} \mathrm{O}\right), 5.46(\mathrm{~d}, J 12.0 \mathrm{~Hz}, \underline{\mathrm{HC}}=\mathrm{CHCN}$, $Z$-isomer), 5.88 (d, $J 16.0 \mathrm{~Hz}, \underline{\mathrm{HC}}=\mathrm{CHCN}, E$-isomer), $7.10(\mathrm{~d}, J 12.0 \mathrm{~Hz}, \mathrm{HC}=\mathrm{CHCN}, Z$-isomer $), 7.10-7.19$ (m, 2H, Ar), $7.38(\mathrm{~d}, J 16.0 \mathrm{~Hz}, \mathrm{HC}=\mathrm{C} \underline{H C N}, E$-isomer), 7.43 (d, $J 8.0 \mathrm{~Hz}, 1 \mathrm{H}, \mathrm{Ar}$ ), 7.50-7.63 (m, 3H, Ar), 7.66$7.73(\mathrm{~m}, 2 \mathrm{H}, \mathrm{Ar}), 7.81(\mathrm{~d}, J 8.4 \mathrm{~Hz}, 1 \mathrm{H}, \mathrm{Ar}), 7.98$ (m, $1 \mathrm{H}, \mathrm{Ar}) ;{ }^{13} \mathrm{C}$ NMR $\left(100 \mathrm{MHz}, \mathrm{CDCl}_{3}\right) \delta 14.1,22.6,26.1$, 29.2, 29.3, 29.4, 29.5, 29.6, 31.9, 68.1, 88.3 (E-isomer), 88.5 (Z-isomer), 92.9 (Z-isomer), 93.1 ( $E$-isomer), 95.2 (Z-isomer), 96.6 ( $E$-isomer), 106.5, 117.3 ( $E$-isomer), 117.4 (Z-isomer), 118.0, 119.8 (Z-isomer), 119.9 (E-isomer), 126.2 (Z-isomer), 126.5 ( $E$-isomer), 126.8 ( $Z$-isomer), 126.9 (E-isomer), 127.3, 128.2 ( $Z$-isomer), 128.3 ( $E$-isomer), 128.7 ( $E$-isomer), 128.8 ( $Z$-isomer), 129.0 (Z-isomer), 129.3 ( $E$-isomer), 131.6, 131.9 (Z-isomer), 132.1 ( $E$-isomer), 132.8 ( $E$-isomer), 132.9 (Z-isomer), 134.4 (Z-isomer), 134.5 ( $E$-isomer), 147.7 (Z-isomer), 149.6 ( $E$-isomer), 158.0 (Z-isomer), 158.1 ( $E$-isomer).

\section{Results and Discussion}

Scheme 2 illustrates the synthetic route to obtain the aldehydes $\mathbf{4}$ and $\mathbf{5}$. They were prepared in four steps according to a previously described methodology. ${ }^{31-33}$ Alkynes $\mathbf{1}$ and $\mathbf{2}$ were prepared following methods already described in the literature ${ }^{31}$ and they were combined with

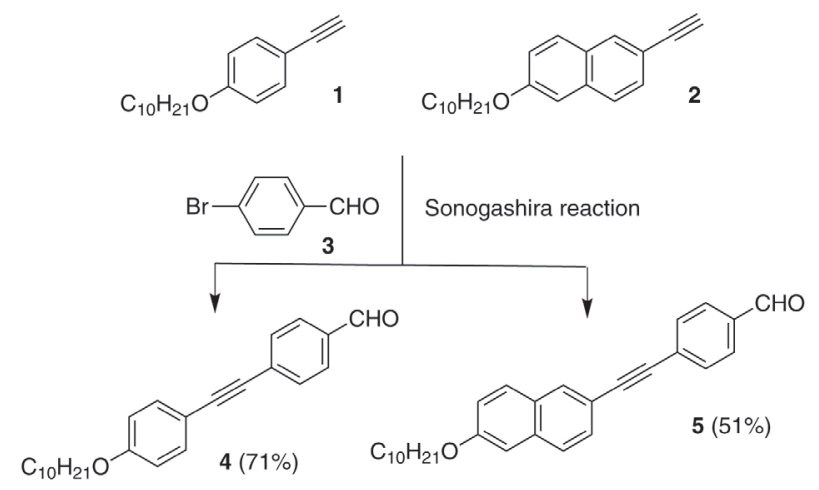

Scheme 2. Synthetic route to prepared 4 and $\mathbf{5}$. Reaction conditions: $\mathrm{NEt}_{3}$, $\mathrm{CuI}, \mathrm{PPh}_{3},\left[\mathrm{PdCl}_{2}\left(\mathrm{PPh}_{3}\right)_{2}\right]$, argon and reflux for $48 \mathrm{~h}$. 
bromobenzaldehyde (3) through the Sonogashira reaction to yield chromophores $\mathbf{4}$ and $\mathbf{5}$. ${ }^{31-33}$

Scheme 3 describes the synthesis of cinnamic acids and acrylonitrile derivatives. The installation of an electronwithdrawing group allows the effect of the acceptor fragment on thermal and photophysical properties of compounds 8-12 to be evaluated. All new compounds were satisfactorily characterized as described in the Experimental section. The final molecules were obtained by Knoevenagel condensation of aldehydes $\mathbf{4}$ or $\mathbf{5}$ in the following way: (i) cinnamic acid derivatives 8 and 9 were prepared by reaction of aldehyde 4 or 5 with malonic acid in the presence of piperidine and pyridine under heating for 2 days; ${ }^{34}$ (ii) cyano derivatives 10, 11, and 12 were prepared by reacting cyanoacetic acid and aldehyde 4 or $\mathbf{5}$ in the presence of morpholine (or pyridine) in acetonitrile (reflux for 3 days). ${ }^{35}$ The yields of the final compounds were determined after crystallization or by long and exhaustive chemical purifications through chromatographic columns. While $\mathbf{1 0}$ is a mixture of E/Z-isomers, compounds $\mathbf{1 1}$ and 12 were collected by chromatographic columns and characterized as $E$-isomer and Z/E-isomers, respectively. Compounds $\mathbf{1 1}$ and $\mathbf{1 2}$ were obtained from the same reaction vessel, and by a long and exhaustive separation process $E$-isomer was collected first and the second fraction collected was characterized as being $E / Z$-isomers. Attempts to separate E/Z-isomers from $\mathbf{1 0}$ has failed and it was analyzed as mixture of isomers. For Knoevenagel condensation to produce $\mathbf{1 0}, \mathbf{1 1}$ and $\mathbf{1 2}$, the aldehydes 4 and $\mathbf{5}$ were quite sluggish to react, giving unsaturated nitriles in low yields. Attempts to isolate pure $(E)$ - $\alpha$-cyanocinnamic acid have failed and a mixture of E/Z-cinnamonitrile was obtained, probably due to the prolonged treatment in boiling acetonitrile, which induces spontaneous decarboxylation of tetrahedral intermediate formed in the addition step. ${ }^{35}$

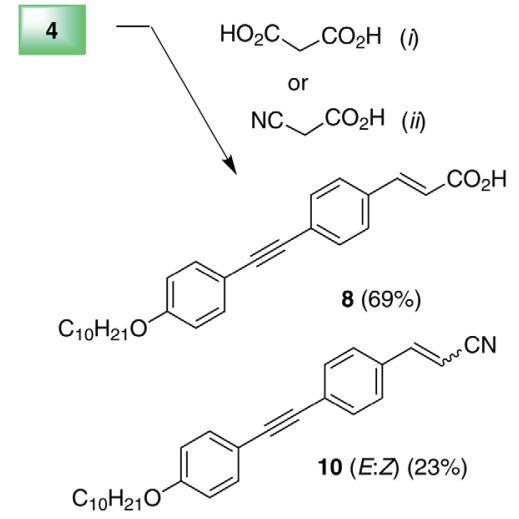

The Knoevenagel condensation reactions showed different selectivity in the formation of the cinnamic acids 8 and 9 and acrylonitriles 10, 11 and 12. The reaction carried out with malonic acid was selective exclusively for the $E$-isomer configuration for $\mathbf{8}$ and $\mathbf{9}$. The condensation reaction with cyanoacetic acid yielded a mixture of $E / Z$ geometrical isomers. As discussed in the above paragraph, a fraction of pure $E$-isomer $\mathbf{1 1}$ was obtained by separation process from the E/Z-isomers mixture of $\mathbf{1 2}$. The ${ }^{1} \mathrm{H} N M R$ spectra, recorded in $\mathrm{CDCl}_{3}$ at room temperature, for compounds 9, 11 and $\mathbf{1 2}$ are shown in Figure 1. The spectra for these final compounds show a very distinctive signal assigned to the vinylic protons. Compounds which showed a lower $\delta$ value for vinylic protons were assigned as $Z$-isomers and the other compounds as $E$-isomers. The spectrum of the $E$-isomer of 9 in Figure 1a shows doublets at $\delta 6.59\left(\mathrm{H}_{\alpha}\right)$ and $7.62 \mathrm{ppm}\left(\mathrm{H}_{\beta}\right)$ with a typical coupling constant of $J 16.2 \mathrm{~Hz}$, related to the pure (E)-9 isomer. In Figure 1b, the spectrum for the $E$-isomer of $\mathbf{1 1}$ has two doublets at $\delta 5.88\left(\mathrm{H}_{\alpha}\right)$ and $7.38 \mathrm{ppm}\left(\mathrm{H}_{\beta}\right)$ with a coupling constant of $J 16.0 \mathrm{~Hz}$. Figure 1c shows the ${ }^{1} \mathrm{H}$ NMR spectrum for a mixture of $E / Z$-isomers of $\mathbf{1 2}$. The $Z$-isomers display two doublets for vinylic protons at $\delta 5.46\left(\mathrm{H}_{\alpha}\right)$ and $7.10 \mathrm{ppm}\left(\mathrm{H}_{\beta}\right)$ with a typical coupling constant of $J 12.0 \mathrm{~Hz}$. In the same spectrum there are also two additional doublets for $E$-isomers of the vinylic protons at $\delta 5.88\left(\mathrm{H}_{\alpha}\right)$ and $7.38 \mathrm{ppm}\left(\mathrm{H}_{\beta}\right)$, with a typical coupling constant of $J 16.0 \mathrm{~Hz}{ }^{36}$ The integration of vinylic signals allowed the proportion of $E / Z$-isomers of sample 12 to be determined as $32 \% E$ and $68 \% Z$-isomers. Thus, vinylic protons at high frequency (low field) refer to the $E$-isomer, while at low frequency (high field) they refer to the $Z$-isomer. This assignment is further confirmed by the ${ }^{1} \mathrm{H}$ NMR spectrum for the pure compound (E)-11 without

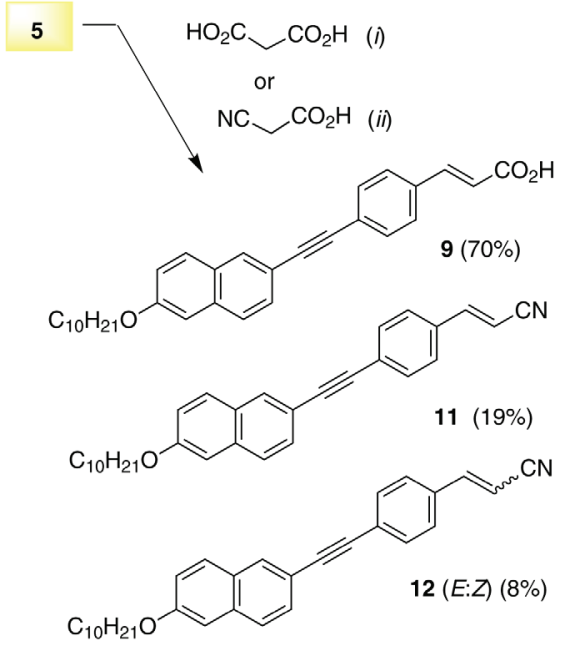

Scheme 3. Reaction conditions for preparation of 8-12: (i) $\mathrm{CH}_{2}\left(\mathrm{CO}_{2} \mathrm{H}\right)_{2}$, piperidine, pyridine, reflux, 2 days; $\mathrm{R}=\mathrm{C}_{10} \mathrm{H}_{21} ;$ (ii) $\mathrm{NCCH}_{2} \mathrm{CO}_{2} \mathrm{H}$, morpholine, acetonitrile, reflux, 3 days. 
its $Z$-isomer, where the $E$-vinylic protons appear as a doublet at $\delta 5.88\left(\mathrm{H}_{\alpha}\right)$ and $7.38 \mathrm{ppm}\left(\mathrm{H}_{\beta}\right)$ (Figure 1b) with a coupling constant of $J 16.0 \mathrm{~Hz}$, confirming the correct assignment of the geometric isomers. ${ }^{36,37}$ In addition, the electron-withdrawing group effect is observed by comparing the pure isomers $(E)-\mathbf{1 1}$ and $(E)-\mathbf{9}$ in the ${ }^{1} \mathrm{H}$ NMR spectrum, as evidenced by the appearance of signals at high frequency for the $E$-isomer containing the carboxyl group and low frequency (high field) for the $E$-isomer of the nitrile group. The same analysis was applied to $(E)-\mathbf{8}$ and $(E / Z)-\mathbf{1 0}$ and compound $\mathbf{8}$ displayed doublets at $\delta 6.43\left(\mathrm{H}_{\alpha}\right)$ and $7.65 \mathrm{ppm}\left(\mathrm{H}_{\beta}\right)$, while for $\mathbf{1 0}$ the $E$-isomer displayed two doublets at $\delta 5.87\left(\mathrm{H}_{\alpha}\right)$ and $7.37 \mathrm{ppm}\left(\mathrm{H}_{\beta}\right)$ and $Z$-isomer showed doublets at $\delta 5.45$ $\left(\mathrm{H}_{\alpha}\right)$ and $7.10 \mathrm{ppm}\left(\mathrm{H}_{\beta}\right)$.

When compound $\mathbf{1 1}$ was subjected to the magnetic field in the ${ }^{13} \mathrm{C}$ NMR analysis, the carbon atom of the $-\mathrm{CN}$ group appeared at $117.3 \mathrm{ppm}$ while the corresponding carbon atom in the (Z)-12 appeared at $117.4 \mathrm{ppm}$. In addition, the carbon atom of the olefinic group in the $(E)-\mathbf{1 2}$ appeared at $96.6\left(\mathrm{C}_{\alpha}\right)$ ppm while corresponding carbon atom in (Z)-12 appeared at $95.2 \mathrm{ppm}\left(\mathrm{C}_{\alpha}\right)$. On the other hand, the other carbon atom of the olefin group of the molecule with (Z)-12 appeared at $147.7 \mathrm{ppm}\left(\mathrm{C}_{\beta}\right)$, while the corresponding carbon atom in $(E)$-12 appeared at $149.6 \mathrm{ppm}\left(\mathrm{C}_{\beta}\right)$. The assignment of the spectral data for the chromophores in this study is in accordance with that of similar compounds reported in the literature. ${ }^{37}$

\section{Liquid-crystal behavior}

The transition temperatures of compounds 8-12 and intermediates 4-5 are summarized in Table 1. The transition temperatures, textures and images of the mesophase (Figure 2) were obtained using polarized optical microscopy (POM). DSC experiments were recorded for final samples. However, DSC traces in the first heating stage displayed the thermal history of the samples and attempts to perform the second and third heating/cooling cycles were unproductive due to thermal decomposition at high temperatures (above the clearing temperatures). Thus, the DSC data are not included in Table 1.

Table 1. Mesophases and transition temperatures for compounds 4, 5, 8, $9,10,11$ and 12 upon heating

\begin{tabular}{|c|c|}
\hline Compound & Transition temperature $/{ }^{\circ} \mathrm{C}$ \\
\hline 4 & Cr 85 I \\
\hline 5 & Cr 111 N 135 I \\
\hline 8 & Cr 206 SmC $260 \mathrm{~N}$ dec. I \\
\hline 9 & Cr 220 SmC $278 \mathrm{~N}$ dec. I \\
\hline 10 & Cr 89 SmA 159 I \\
\hline 11 & Cr 110 SmA 152 N 185 I \\
\hline 12 & Cr 101 SmA 163 N 198 I \\
\hline
\end{tabular}

Data were recorded by POM. Cr: crystal phase; I: isotropic phase; $\mathrm{N}$ : nematic mesophase; SmA and SmC: smectic A and C mesophase.

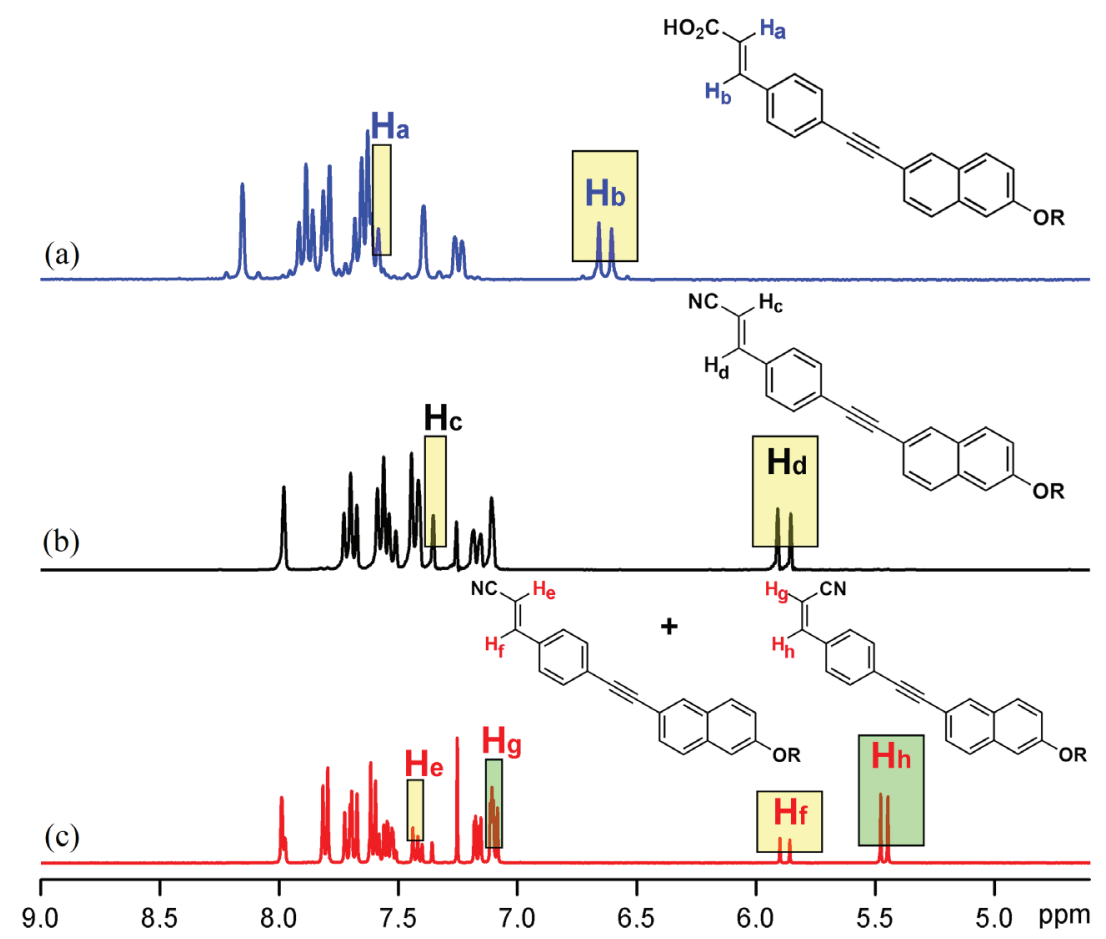

Figure 1. Magnification of a region of the ${ }^{1} \mathrm{H}$ NMR spectra (400 MHz, $\mathrm{CDCl}_{3}$ ) for compounds (a) $\mathbf{9}$ ( $E$-isomer); (b) $\mathbf{1 1}$ ( $E$-isomer); (c) $\mathbf{1 2}$ (32\% of $E$ and $68 \%$ of $Z$-isomers). 


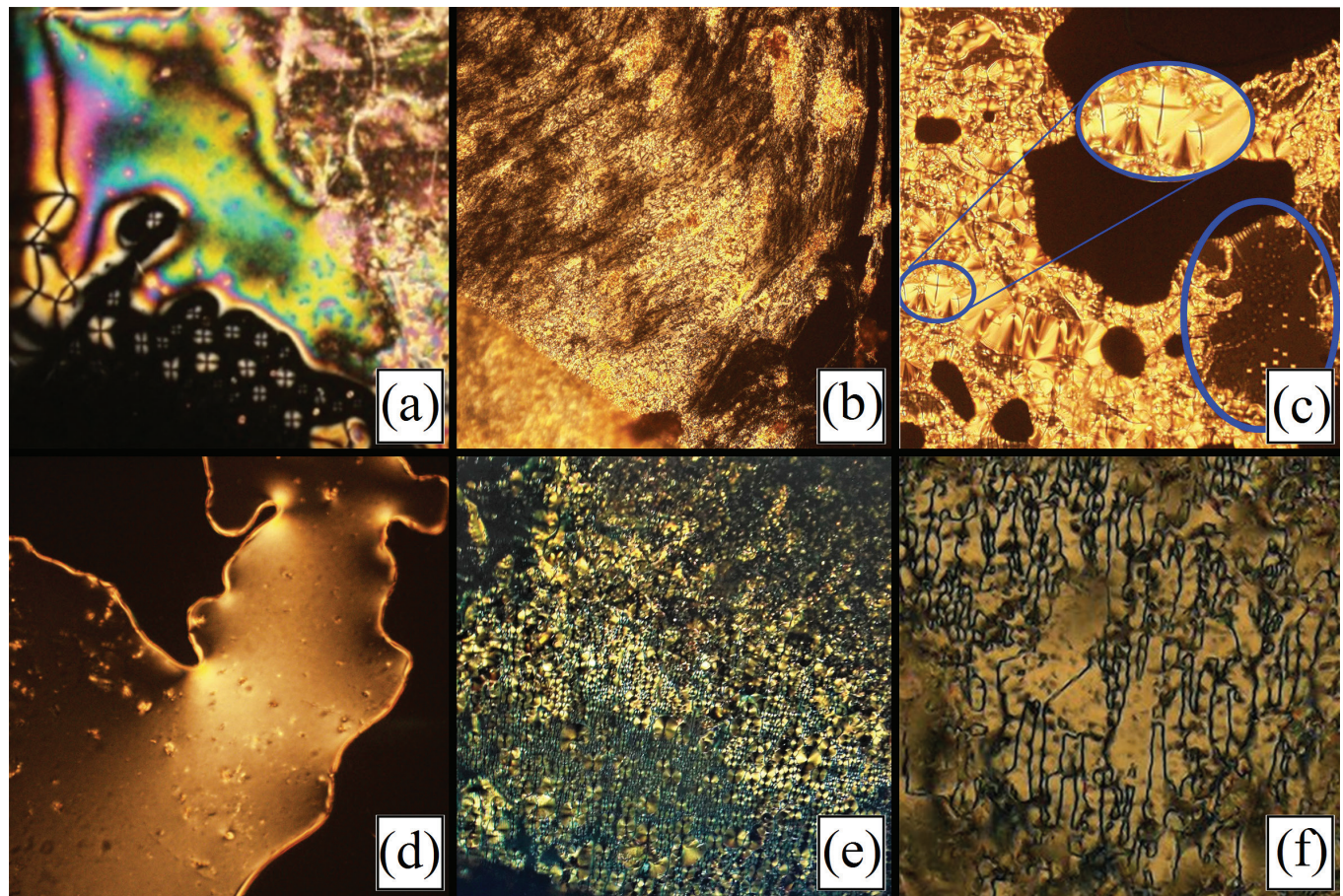

Figure 2. POM images of the compounds: (a) $\mathbf{5}$ (schlieren texture, at right, two- and four-fold disclination lines; at left, marble texture; and some Maltese cross below, for nematic phase, upon heating at $134^{\circ} \mathrm{C}$ ); (b) $\mathbf{9}$ (blurred schlieren texture for SmC mesophase, upon heating to $226{ }^{\circ} \mathrm{C}$ ); (c) 10 (fan-focal conic texture for SmA mesophase along black and irregular air bubbles, upon cooling to $148^{\circ} \mathrm{C}$. Focal-conic domains (FCDs) present optical discontinuities, being visible in ordinary light and with crossed polarized, and they appear as dark lines. The dark lines form the ellipses and hyperbole in the conics geometry, which are highlighted in Figure 2c. In a special case, FCDs can display an ellipse as a circle and hyperbole as straight line); (d) 11 (nematic phase with flashing effect, phase director instabilities, upon cooling to $166^{\circ} \mathrm{C}$. Under no stress conditions, samples appear completely black in the interior and colorful in the neighborhood); (e) $\mathbf{1 2}$ (fan-focal conic and radial textures for SmA mesophase, upon cooling to $145{ }^{\circ} \mathrm{C}$ ); (f) $\mathbf{1 2}$ (planar texture for nematic phase, upon heating to $175^{\circ} \mathrm{C}$ ).

In general, aldehyde 4 did not exhibit a mesophase, aldehyde $\mathbf{5}$ showed enantiotropic liquid-crystal behavior with a nematic phase when analyzed by POM (Table 1 and Figure 2a). Cinnamic acids $\mathbf{8}$ and $\mathbf{9}$ showed nematic and smectic $\mathrm{C}(\mathrm{SmC})$ mesophases in the POM analysis, with the mesomorphism range largely dependent on the arylacetylene group. As noted for cinnamic acids $\mathbf{8}$ and $\mathbf{9}$, as well as the acrylonitriles $\mathbf{1 0}, \mathbf{1 1}$ and 12, the naphthylacetylene group favors the mesophase range more than the phenylacetylene group by increasing the length/ width ratio. Another aspect that should be emphasized is the thermal behavior at high temperatures. We noted visually in the POM analysis that the compounds of both series (cinnamic acids and acrylonitriles) started to decompose when they reached the liquid phase at high temperature. Images of the mesophase are generally taken upon cooling from the isotropic state to eliminate residual structural information present in the ordered phase and to capture good quality pictures. Thus, in the liquid state, no information about the order of the system is available and when the sample transits from the isotropic phase to a mesophase some degree of order is added, for instance, orientational order for the nematic phase or translational order for the smectic phase. The texture observed originates from the imperfections of the samples or the glass responsible for the creation of the defects of the phase, which is the texture observed under cross polarized light.

Aldehyde 5 displayed a nematic mesophase (N) (Figure 2a) in contrast with $\mathbf{4}$, which has no mesophase. Compounds 8 and $\mathbf{9}$ presented high melting and clearing temperatures. Upon heating, 8 melted at $180{ }^{\circ} \mathrm{C}$ while 9 melted at $221{ }^{\circ} \mathrm{C}$. Both solids became an anisotropic fluid displaying blurred schlieren texture under heating, suggesting an SmC mesophase, which is present but not clearly observed in Figure 2b. At very high temperatures $\left(>260{ }^{\circ} \mathrm{C}\right.$ ) the nematic mesophase was quickly observed from the schlieren texture. The temperature associated with the transition to the isotropic phase was not registered due to the decomposition of the samples at high temperatures.

For the arylacrylonitrile 10, an elongated rodshaped molecule with a mixture of $E / Z$-isomers displayed stable smectic A (SmA) with a mesophase range of $70{ }^{\circ} \mathrm{C}$. From the isotropic phase, $\mathbf{1 0}$ entered into the $\mathrm{SmA}$ mesophase at $148^{\circ} \mathrm{C}$ and crystallized at $72{ }^{\circ} \mathrm{C}$ (Figure 2c). Investigation of the pure $E$-isomer of $\mathbf{1 1}$ revealed $\mathrm{SmA}$ and $\mathrm{N}$ mesophases. Upon heating, compound $\mathbf{1 1}$ entered into the SmA mesophase at $110{ }^{\circ} \mathrm{C}$ with a fan-focal conic texture, and at $152{ }^{\circ} \mathrm{C}$ the sample entered into the 
$\mathrm{N}$ mesophase with planar texture and at $185^{\circ} \mathrm{C}$ reached the isotropic liquid phase. On cooling from the isotropic phase, 11 displayed a homeotropic texture at $190{ }^{\circ} \mathrm{C}$, as observed in the POM analysis, with characteristic black domains, homeotropic alignment with flashing effects, fast and reversible orientational movements of the phase director (n) (Figure 2d), typical of a nematic phase. The last acrylonitrile (12) was analyzed as a mixture of $E / Z$-isomers and showed enantiotropic SmA and N mesophases. Upon heating, SmA starts at $101{ }^{\circ} \mathrm{C}$ and with further heating up to $163{ }^{\circ} \mathrm{C}$ it transits into the $\mathrm{N}$ mesophase, finally melting into an isotropic liquid at $198^{\circ} \mathrm{C}$. Fan-focal conic and radial textures as well as planar nematic textures for the SmA and $\mathrm{N}$ mesophase, respectively, are seen in Figures $2 \mathrm{e}$ and $2 \mathrm{f}$.

The polar-ended group also has an effect on the liquid crystal properties, as seen for $\mathbf{4 , 8}$ and $\mathbf{1 0}$, which all have same aromatic core. However, the carbonyl group in $\mathbf{4}$ is a less efficient polar group, in terms of the mesophase stabilization, than the carboxyl group (by dimers) in $\mathbf{8}$ or the cyan group (directional dipolar orientation) in $\mathbf{1 0}$. The liquid crystal behavior of a mixture of isomers $(E / Z)-\mathbf{1 0}$ and $(E / Z)-\mathbf{1 2}$ with the pure isomer $(E)-\mathbf{1 1}$ can be observed from the data in Table 1. Comparing the isomers with the naphthylacetylene group, pure $E$-isomer 11 displays higher melting point than $E / Z$-isomer 12. Clearing temperature for the $E / Z$-isomer is $13{ }^{\circ} \mathrm{C}$ above the $E$-isomer 11 . The result here reveals that packing considerations are more important for pure isomer $(E)-\mathbf{1 1}$, as expected. However, anisotropic interactions favor the mesophase range for $(E / Z)-\mathbf{1 2}$, especially for SmA mesophase through lateral diffusion, ${ }^{38}$ probably due to the excess of $Z$-isomer over $E$-isomer in 10 and 12. Another point is related to the length-tobreadth ratio, which is crucial to the thermal stability of the mesophase. The naphthyl group in this class of molecules is a better stabilizer group than phenyl, due to the breadth supplied by naphthyl moieties, as evidenced by the mesophase range, melting point and clearing temperature in Table 1. Thus, in this series, the mesophase stability follows the order: naphthylacetylene group > phenylacetylene group (tolane unit) ${ }^{31,32}$ and others. ${ }^{39}$

\section{Thermal stability of organic compounds}

The thermal properties of cinnamic acids $\mathbf{8}$ and $\mathbf{9}$ and acrylonitrile $\mathbf{1 0}$ and $\mathbf{1 2}$ were investigated by TGA under $\mathrm{N}_{2}$ atmosphere to determine exactly when the decomposition phenomena occurs. Figure 3 shows two degradation peaks in the thermogravimetry-derivative thermogravimetry (TG-DTG) curves, which correspond to degradation of the material in two steps in the range of 50 to $500{ }^{\circ} \mathrm{C}$. For $\mathbf{1 0}$ and $\mathbf{8}$ the second peak is less intense than in the case of
12 and $\mathbf{9}$. While $\mathbf{1 0}$ and $\mathbf{8}$ contain alkoxyphenylacetylene units, alkoxynaphthylacetylene is present in $\mathbf{1 2}$ and $\mathbf{9 .}$ Above $500{ }^{\circ} \mathrm{C}$, the residual solid that remains is higher for the compounds that contain the naphthalene ring in their structure.

The TG-DTG curves for compounds 8 and 9 displayed two weight loss peaks, as seen in Figures $3 \mathrm{a}$ and $3 \mathrm{~b}$. For compound $\mathbf{8}$, the weight loss of around $70 \%$ in the region of $210-360{ }^{\circ} \mathrm{C}$ is related to the elimination of cinnamic acid and the decyloxy chain. The weight loss between 384 and $500{ }^{\circ} \mathrm{C}$ (around $14 \%$ ) could be assigned to a loss of volatile materials from residual material that remains above $500{ }^{\circ} \mathrm{C}$. For 9, it can be seen from Figure $3 \mathrm{~b}$ that the first degradation process occurs in the region of $235-385^{\circ} \mathrm{C}$ with weight loss of around $15 \%$, which is related to butenoic acid elimination. The weight loss between 385 and $500{ }^{\circ} \mathrm{C}$ (around $21 \%$ ) could be assigned to loss of the phenyl group. The remaining residue (around 64\%) is material resulting from the decomposition above $500{ }^{\circ} \mathrm{C}$. For acrylonitrile 10, the first degradation peak in Figure $3 \mathrm{c}$ is in the region of $250-380{ }^{\circ} \mathrm{C}$, with the weight loss of around $68 \%$ related to the elimination of the cinnamonitrile and decyl groups. The weight loss between 400 and $500{ }^{\circ} \mathrm{C}$ (around 16\%) could be assigned to the loss of low molecular weight volatiles, such as water for phenylacetylene, and above $500{ }^{\circ} \mathrm{C}$ a residual material (char) remains. In the case of $\mathbf{1 2}$ (Figure 3d), the peaks on the TG-DTG curves in the region of $280-390{ }^{\circ} \mathrm{C}$ may be related to a weight loss of around $39 \%$ associated with the decyloxy chain. The weight loss between 390 and $500{ }^{\circ} \mathrm{C}$ (around $18 \%$ ) could be assigned to the elimination of the acrylonitrile unit. The residue (around 40\%) is a char material composed of high molecular weight materials derived from naphthylphenylacetylene.

\section{Photophysical properties, absorption and fluorescence}

The photophysical properties of compounds 8-12 and intermediates 4-5 are shown in Table 2. Absorption and fluorescence spectra were taken in diluted solutions of chloroform $\left(10^{-5} \mathrm{M}\right)$ and the representative spectra are given in Figure 4. All molecules exhibited absorption between 300 and $400 \mathrm{~nm}$, with maxima close to $340 \mathrm{~nm}$. These absorption bands are assigned to $\pi-\pi^{*}$ transitions due to their high molar absorption coefficients $\left(\varepsilon=3.0-6.8 \times 10^{4} \mathrm{~L} \mathrm{~mol}^{-1} \mathrm{~cm}^{-1}\right)$. The naphthyl group in the rigid core clearly shifted the absorbance of the compounds to longer wavelengths (ca. $10 \mathrm{~nm}$ ) when compared to phenyl systems. The terminal groups showed bathochromic shifts in the following order: acrylonitrile > carboxylic acid > aldehyde, according to the nature of the withdrawing effect of these groups. 

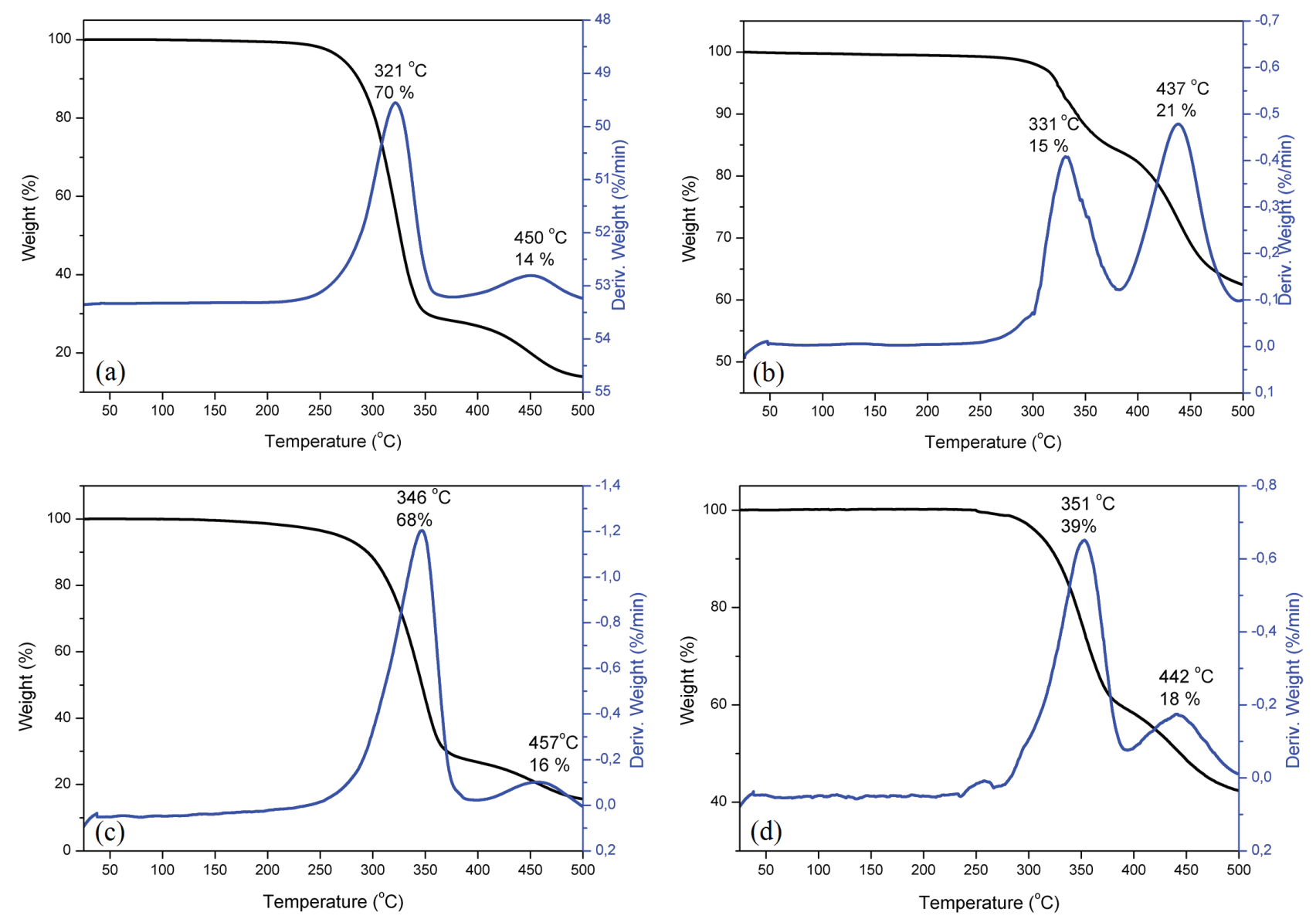

Figure 3. TG and DTG thermograms of compounds (a) 8; (b) 9; (c) 10 and (d) $12\left(\mathrm{~N}_{2}\right.$ flow of $25 \mathrm{~mL} \mathrm{~min}^{-1}$ with a heating rate of $10{ }^{\circ} \mathrm{C}$ min $\left.{ }^{-1}\right)$.

Table 2. Summary of photophysical properties of 4, 5 and 8-12 compounds

\begin{tabular}{lcccc}
\hline Sample & \multicolumn{2}{c}{$\lambda_{\max } / \mathrm{nm}$} & Stokes shift $/ \mathrm{cm}^{-1}$ & \multirow{2}{*}{$\Phi_{\mathrm{PL}}{ }^{\mathrm{c}}$} \\
\cline { 2 - 4 } & Absorption $\left(\varepsilon /\left(10^{4} \mathrm{~L} \mathrm{~mol}^{-1} \mathrm{~cm}^{-1}\right)\right)$ & Emission $^{\mathrm{a}, \mathrm{b}}$ & 6047 & 0.07 \\
$\mathbf{4}$ & $340(4.3)$ & 428 & 6529 & 0.50 \\
$\mathbf{8}$ & $349(5.3)$ & 452 & 6717 & 0.87 \\
$\mathbf{9}$ & $342(3.2)$ & 444 & 6670 & 0.99 \\
$\mathbf{1 0}$ & $352(3.0)$ & 460 & 5537 & 0.79 \\
$\mathbf{1 1}$ & $346(4.4)$ & 428 & 5768 & 0.86 \\
$\mathbf{1 2}$ & $356(6.7)$ & 448 & 5768 & 0.78 \\
\hline
\end{tabular}

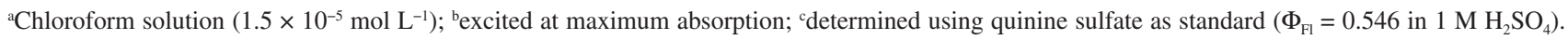
$\varepsilon$ : molar absorption coefficient; $\Phi_{\mathrm{PL}}$ : fluorescence quantum yields.

All compounds exhibited intense fluorescence when excited at the maximum absorption wavelength in solution. Emission peaks were observed from 428 to $460 \mathrm{~nm}$. Once again, for the molecules with naphthyl groups $(\mathbf{5}, \mathbf{9}$ and 11) the peaks were at longer wavelengths when compared to the phenyl systems (Figure 4).

With respect the terminal groups, a hypsochromic shift in the maximum emission wavelength is observed with the replacement of the carboxylic acid group with the cyan group in both phenyl and naphthyl systems. The carboxylic acids $\mathbf{8}$ and $\mathbf{9}$ show maximum emission at 444 and $460 \mathrm{~nm}$, respectively, while the acrylonitriles $\mathbf{1 0}$ and $\mathbf{1 1}$ present emission at 428 and $448 \mathrm{~nm}$. This phenomenon may be related to the more intense electron withdrawing effect of the cyan group. The $E$-isomer $\mathbf{1 1}$ showed exactly the same maxima of absorbance and emission as the mixture of $E: Z$ geometrical isomers 12. The Stokes shifts are in the range of $88-140 \mathrm{~nm}\left(5537-6717 \mathrm{~cm}^{-1}\right)$ with a small 

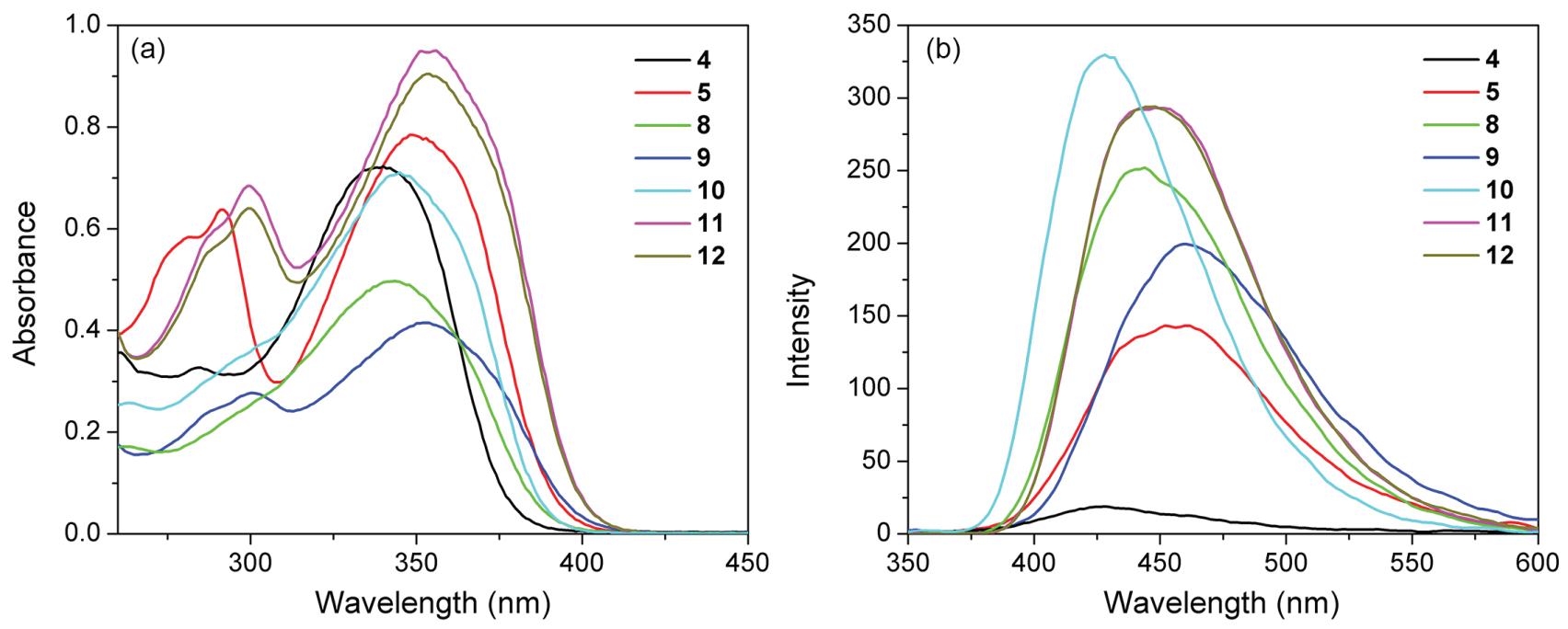

Figure 4. Absorbance (a) and emission (b) spectra for compounds 4, 5 and 8-12 in chloroform solution $\left(10^{-5} \mathrm{~mol} \mathrm{~L}^{-1}\right)$.

region of coincidence between the absorption and emission. The molecules exhibited fluorescence quantum yields $\left(\Phi_{\mathrm{PL}}\right)$ of between 0.07 and 0.99 relative to the standard quinine sulfate (Table 2) ${ }^{40}$ In general, the naphthyl derivatives (5, $9,11)$ showed higher quantum yields when compared to the phenyls $(4,8,10)$, probably due the greater $\pi$-extended conjugation. The phenyl- (4) and naphthyl-aldehyde (5) intermediates exhibited the lowest quantum yields of the series ( 0.07 and 0.50 , respectively). On the other hand, the photoluminescence efficiency of the carboxylic acids $\mathbf{8}$ and 9 was slightly higher than that of the acrylonitrile derivatives (0.87 and 0.99 , respectively). Through the photophysical study it was possible to observe that the $E$-isomer of acrylonitrile (11) presented a superior quantum yield than the $E: Z$ mixture (12).

\section{Solvatochromism properties}

In order to investigate the solvatochromic properties of the compounds, the absorption and fluorescence spectra of $\mathbf{8 , 9}$ and 11 were obtained in diluted solutions of heptane, acetone, acetonitrile, chloroform, dimethylformamide, tetrahydrofuran, toluene, ethyl acetate and ethanol. ${ }^{41}$ The optical properties were measured in heptane, acetone, acetonitrile, chloroform, dimethylformamide (DMF), tetrahydrofuran (THF), toluene, ethyl acetate and ethanol solutions. Figure 5 shows the normalized emission spectra for sample $\mathbf{1 1}$ in solvents of different polarities and their optical data are summarized in Table 3. Small spectral variations are observed for the absorption spectra of these samples regardless of the polarity of the solvents. However, a significant increase in the red-shift of the fluorescence spectra as the polarity solvent increases was observed. The maximum emissions of compound $\mathbf{1 1}$ were shifted

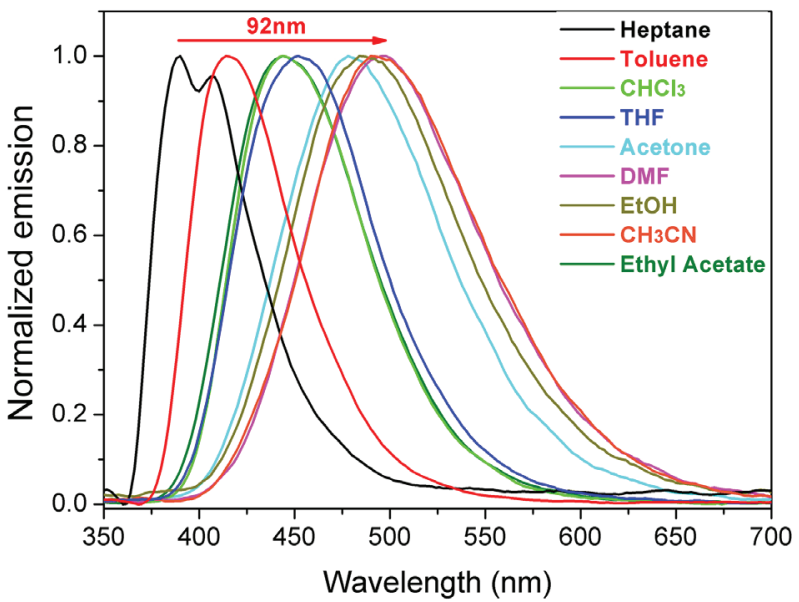

Figure 5. Normalized emission spectra for acrylonitrile $\mathbf{1 1}$ in different solvents.

Table 3. Absorption and emission data for compound $\mathbf{1 1}$ in different solvents

\begin{tabular}{|c|c|c|c|}
\hline \multirow[b]{2}{*}{ Solvent } & \multicolumn{2}{|c|}{$\lambda_{\max } / \mathrm{nm}$} & \multirow{2}{*}{$\begin{array}{c}\text { Stokes shift / } \\
\mathrm{cm}^{-1}\end{array}$} \\
\hline & $\begin{array}{c}\text { Absorption }{ }^{\mathrm{a}} \\
\left(\varepsilon /\left(\mathrm{L} \mathrm{mol}^{-1} \mathrm{~cm}^{-1}\right)\right)\end{array}$ & Emission $^{\mathrm{b}}$ & \\
\hline Heptane & $350\left(1.0 \times 10^{4}\right)$ & 402 & 3696 \\
\hline Toluene & $352\left(3.4 \times 10^{4}\right)$ & 416 & 4371 \\
\hline $\mathrm{CHCl}_{3}$ & $353\left(6.7 \times 10^{4}\right)$ & 450 & 6106 \\
\hline THF & $349\left(3.6 \times 10^{4}\right)$ & 454 & 6627 \\
\hline Acetone & $344\left(3.4 \times 10^{4}\right)$ & 480 & 8236 \\
\hline DMF & $349\left(3.3 \times 10^{4}\right)$ & 492 & 8328 \\
\hline $\mathrm{CH}_{3} \mathrm{CN}$ & $346\left(3.0 \times 10^{4}\right)$ & 494 & 8659 \\
\hline $\mathrm{EtOH}$ & $348\left(2.1 \times 10^{4}\right)$ & 488 & 8244 \\
\hline Ethyl acetate & $346\left(3.3 \times 10^{4}\right)$ & 446 & 6480 \\
\hline
\end{tabular}

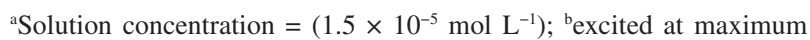
absorption. $\varepsilon$ : molar absorption coefficient; THF: tetrahydrofuran; DMF: dimethylformamide. 
from 402 (heptane) to $494 \mathrm{~nm}$ (acetonitrile), representing a variation of $92 \mathrm{~nm}$.

The increase in the red-shift of the fluorescence spectra or the Stokes' shift as the polarity solvent increases is consistent with the stabilization of the excited states by the polar solvents. ${ }^{42}$ This process, called solvent relaxation, indicates that the excited state of these compounds is more polar than the ground state. Similar behavior of absorption and emission spectra were observed for compounds $\mathbf{8}$ and 9. These samples also presented emission bands shifted to longer wavelengths with an increase in the solvent polarity.

The influence of solvent polarity on the optical properties of a fluorophore can be estimated using the Lippert-Mataga equation. ${ }^{43,44}$ The plot of the Stokes shifts $(\Delta v)$ as a function of orientation polarizability $(\Delta \mathrm{f})$ for $\mathbf{1 1}$ is shown in Figure 6. The increase in $\Delta v$ with an increase in the solvent polarity parameter leads to a linear correlation of 0.976 .

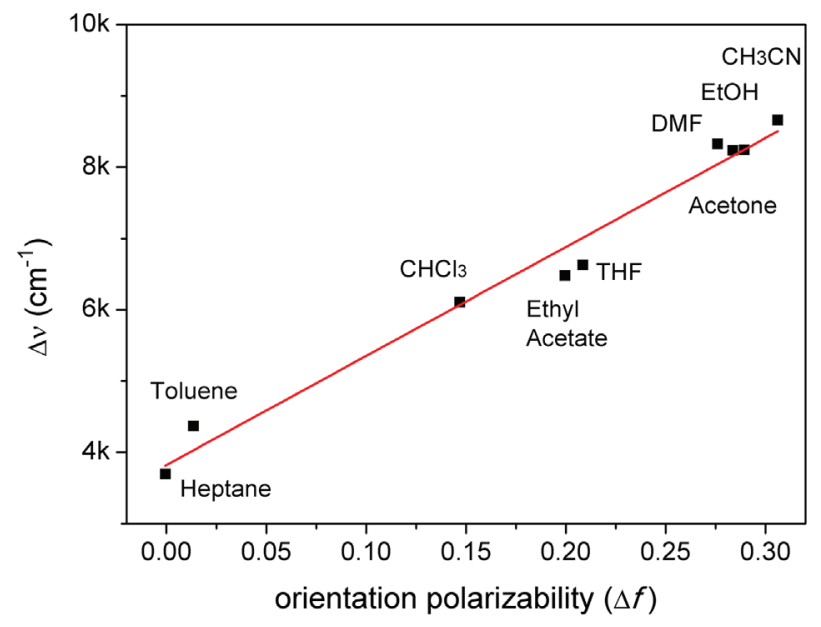

Figure 6. Changes in the Stokes shifts $(\Delta v)$ of $\mathbf{1 1}$ versus $\Delta \mathrm{f}$ of various solvents.

The calculated values for the slope of the linear correlation for these compounds showed that the slopes became steep in the order of $\mathbf{1 1}\left(15300 \mathrm{~cm}^{-1}\right)>$ $8\left(12300 \mathrm{~cm}^{-1}\right)>\mathbf{9}\left(12900 \mathrm{~cm}^{-1}\right)$. These results indicate that the optical properties of these compounds show different degrees of solvent dependence and for these samples, the acrylonitrile $\mathbf{1 1}$ exhibits the steepest slope, indicating the largest fluorescence solvatochromism.

\section{Conclusions}

In summary, we prepared new derivatives of acrylic acids 8 and 9 and acrylonitriles 10,11 and $\mathbf{1 2}$. Compounds 10 and $\mathbf{1 2}$ were isolated as a mixture of $Z / E$-isomers while the other compounds were characterized as pure $E$-isomers. Chromophores displayed N, SmA and SmC mesophases, and mesophase range for chromophores was dependent on the nature of arylacetylene group. Despite of enantiotropic mesophase range, the main drawback are their relatives high melting point and thermal decomposition above $250{ }^{\circ} \mathrm{C}$ as noted for $\mathbf{8}$ and $\mathbf{9}$, that limit for practical applications. Photophysical properties of the final compounds were influenced by the phenyl and naphthyl units, as well as the peripheral groups. These molecules exhibited strong blue fluorescence with maxima between 428 and $460 \mathrm{~nm}$ and significant quantum yields (0.78-0.99) in solution. The solvatochromism studies showed that the excited state of these compounds is more polar than their ground state, which led to a red-shift of the fluorescence spectra as the solvent polarity increased. The photophysical results reported herein make these systems promising candidates to be applied in optoelectronic devices.

\section{Supplementary Information}

Supplementary data $\left({ }^{1} \mathrm{H}\right.$ NMR, ${ }^{13} \mathrm{C}$ NMR and FTIR spectra) are available free of charge at https://jbcs.sbq.org.br as PDF file.

\section{Acknowledgments}

We are grateful to MCTI/CNPq for Ed. Universal grant number 403075/2016-5 and 422750/2018-2, FAPERGS Edital PqG 002/2014 for grant number 2280-2551/14-0, and FAPESB (PIBIC) for financial support. This study was financed in part by the Coordenação de Aperfeiçoamento de Pessoal de Nível Superior, Brazil (CAPES), finance code 001 .

\section{Author Contributions}

Aline Tavares, Caroline S. B. Weber, Marco A. Ceschi were responsible for the investigation, data curation, formal analysis (synthesis, spectral and thermal data); Rebeca O. Costa, Thiago Cazati, André A. Vieira for the investigation, data curation, formal analysis (UV and fluorecence data); Aloir A. Merlo for the conceptualization, project administration, resources; André A. Vieira and Aloir A. Merlo also were responsible for writing original draft, review and editing.

\section{References}

1. Guzman, J. D.; Molecules 2014, 19, 19292.

2. Martínez-Abadía, M.; Robles-Hernández, B.; de la Fuente, M. R.; Giménez, R.; Ros, M. B.; Adv. Mater. 2016, 28, 6586.

3. Shanker, G.; Rao, D. S.; Prasad, S. K.; Yelamaggad, C. V.; Tetrahedron 2012, 68, 6528. 
4. Guo, H.; Lin, L.; Qiu, J.; Yang, F.; RSC Adv. 2017, 7, 53316.

5. Clifford, M. N.; J. Sci. Food Agric. 1999, 79, 362.

6. Jimenez, D. E. Q.; Zanin, L. L.; Diniz, L. F.; Ellena, J.; Porto, A. L. M.; Curr. Microwave Chem. 2019, 6, 54.

7. Magarian, E. O.; Nobles, W. L.; J. Pharm. Sci. 1969, 58, 1167.

8. Parveen, M.; Malla, A. M.; Alam, M.; Ahmad, M.; Rafiq, S.; New J. Chem. 2014, 38, 1655.

9. Briguglio, I.; Laurini, E.; Pirisi, M. A.; Piras, S.; Corona, P.; Fermeglia, M.; Pricl, S.; Carta, A.; Eur. J. Med. Chem. 2017, 141,460

10. Praveen, P. L.; Ojha, D. P.; J. Mol. Liq. 2012, 169, 110.

11. Kumavat, P. P.; Baviskar, P. K.; Sankapal, B. R.; Dalal, D. S.; New J. Chem. 2016, 40, 634.

12. Percino, M. J.; Chapela, V. M.; Pérez-Gutiérrez, E.; Cerón, M.; Soriano, G.; Chem. Pap. 2011, 65, 42.

13. Sharma, V. S.; Singh, H. K.; Sharma, A. S.; Shah, A. P.; Shah, P. A.; New J. Chem. 2019, 43, 15575.

14. Lu, H.; Zhang, S.; Ding, A.; Yuan, M.; Zhang, G.; Xu, W.; Zhang, G.; Wang X.; Qiu, L.; Yang, J.; New J. Chem. 2014, 38, 3429.

15. He, W.-L.; Wei, M.-J.; Yang, H.; Yang, Z.; Cao, H.; Wang, D.; Phys. Chem. Chem. Phys. 2014, 16, 5622.

16. Bhola, G. N.; Maheta, R. H.; Bhoya, U. C.; Mol. Cryst. Liq. Cryst. 2015, 623, 129.

17. Shankerz, G.; Yelamaggad, C. V.; New J. Chem. 2012, 36, 918.

18. Muniya, N. R.; Patel, V. R.; Mol. Cryst. Liq. Cryst. 2016, 638, 77.

19. da Rosa, R. R.; Tariq, M.; Weber, C. S. B.; Hameed, S.; Silva, S.; Merlo, A. A.; Liq. Cryst. 2016, 43, 1659.

20. D’Auria, M.; Racioppi, R.; Tetrahedron 1997, 53, 17307.

21. Kawatsuki, N.; Matsuda, T.; Kondo, M.; Mol. Cryst. Liq. Cryst. 2010, 529, 10.

22. Kim, S. Y.; Shin, S. E.; Shin, D. M.; Mol. Cryst. Liq. Cryst. 2010, 520, 116/[392].

23. Wei, P.; Wang, Y.; Xia, Y.; He, Y.; Wang, Y.; Liq. Cryst. 2019 , $46,176$.

24. Kunzelman, J.; Kinami, M.; Crenshaw, B. R.; Protasiewicz, J. D.; Weder, C.; Adv. Mater. 2008, 20, 119.

25. An, B.-K.; Gierschner J.; Park, S. Y.; Acc. Chem. Res. 2012, 45, 544.

26. Yoon, S.-J.; Kim, J. H.; Kim, K. S.; Chung, J. W.; Heinrich, B.; Mathevet, F.; Kim, P.; Donnio, B.; Attias, A.-J.; Kim, D.; Park, S. Y.; Adv. Funct. Mater. 2012, 22, 61.

27. Zhu, L.; Zhao, Y.; J. Mater. Chem. C 2013, 1, 1059.

28. Martínez-Abadia, M.; Robles-Hernandez, B.; Villacampa, B.; de la Fuente, M. R.; Gimenez, R.; Ros, M. B.; J. Mater. Chem. C 2015, 3, 3038.

29. Perrin, D. D.; Armarego, W. L. F.; Purification of Laboratory Chemicals, $3^{\text {rd }}$ ed.; Pergamon Press: Oxford, 1988.

30. King, A. O.; Negishi, E.; Villani Jr., F. J.; Silveira Jr., A.; J. Org. Chem. 1978, 43, 358.

31. Tavares, A.; Ritter, O. M. S.; Vasconcelos, U. B.; Arruda, B. C.; Schrader, A.; Schneider, P. H.; Merlo, A. A.; Liq. Cryst. 2010,
37, 159; Merlo, A. A.; Tavares, A.; Khan, S.; Santos, M. J. L.; Teixeira. S. R.; Liq. Cryst. 2018, 45, 310.

32. Vasconcelos, U. B.; Merlo, A. A.; Synthesis 2006, 7, 1141; Tavares, A.; Arruda, B. C.; Boes, E. S.; Stefani, V.; Stassen, H. K.; Campo, L. F.; Bechtold, I. H.; Merlo, A. A.; J. Braz. Chem. Soc. 2012, 23, 880 .

33. Vasconcelos, U. B.; Dalmolin, E.; Merlo, A. A.; Org. Lett. 2005 , 7, 1027; Tavares, A.; Toldo, J. M.; Vilela, G. D.; Gonçalves, P. F. B.; Bechtold, I. V.; Kitney, S. T.; Kelly, S. M.; Merlo, A. A.; New J. Chem. 2016, 40, 393.

34. Pawar, H. S.; Wagh, A. S.; Lali, A. M.; New J. Chem. 2016, 40, 4962; Brand, Y. M.; Kouznetsov, V. V.; Puerto, C. E.; Linares, V. C. R.; Castaño, V. T.; Betancur-Galvis, L.; J. Braz. Chem. Soc. 2020, 31, 999.

35. Jones, G.; Org. React. 2011, 204; Ziarani, G. M.; Moradi, R.; Lashgari, N.; Kruger, H. G.; Metal-Free Synthetic Organic Dyes; Elsevier Inc.: Amsterdam, 2018, p. 109; Ziarani, G. M.; Moradi, R.; Lashgari, N.; Kruger, H. G.; Metal-Free Synthetic Organic Dyes; Elsevier Inc.: Amsterdam, 2018, p. 197; Feng, Q.; Zhang, Q.; Lu, X.; Wang, H.; Zhou, G.; Wang, Z.-S.; ACS Appl. Mater. Interfaces 2013, 5, 8982; Wada, S.; Suzuki, H.; Tetrahedron Lett. 2003, 44, 399; Sharma, Y. O.; Degani, M. S.; Green Chem. 2009, 11 526; Wilk, M.; Trzepizur, D.; Koszelewski, D.; Brodzka, A.; Ostaszewski, R.; Bioorg. Chem. 2019, 93, 102816.

36. Ruan, J.; Li, X.; Saidi, O.; Xiao, J.; J. Am. Chem. Soc. 2008, 130, 2424; Fang, F.; Li, Y.; Tian, S.-K.; Eur. J. Org. Chem. 2011, 2011,1084

37. Andrus, M. B.; Song, C.; Zhang, J.; Org. Lett. 2002, 4, 2079; Kojima, S.; Fukuzaki, T.; Yamakawa, A.; Murai, Y.; Org. Lett. 2004, 6, 3917.

38. Fritsch, L.; Baptista, L. A.; Bechtold, I. H.; Araújo, G.; Mandle, R. J.; Merlo, A. A.; J. Mol. Liq. 2020, 298, 111750.

39. Prajapati, A. K.; Patel, H. N.; Liq. Cryst. 2007, 34, 903 and references cited therein; Kihara, H.; Tamaoki, N.; Liq. Cryst. 2007, 34, 1337; Dave, J. S.; Vora, R. A.; Mol. Cryst. Liq. Cryst. 1971, 14, 319.

40. Fery-Forgues, S.; Lavabre, D.; J. Chem. Educ. 1999, 76, 1260.

41. Marini, A.; Muñoz-Losa, A.; Biancardi, A.; Mennucci, B.; J. Phys. Chem. B 2010, 114, 17128.

42. Monçalves, M.; Zanotto, G. M.; Toldo, J. M.; Rampon, D. S.; Schneider, P. H.; Gonçalves, P. F. B.; Rodembush, F. S.; Silveira, C. C.; RSC Adv. 2017, 7, 8832.

43. Lakowicz, J. R.; Principles of Fluorescence Spectroscopy; Springers: New York, USA, 2006.

44. Noboru, M.; Yozo, K.; Masao, K.; Bull. Chem. Soc. Jpn. 1956, 29,465 .

Submitted: May 19, 2020

Published online: August 7, 2020 